\title{
DO HOMEM ORGANIZACIONAL À ORGANIZAÇÃO HUMANA: AS BASES PSICOLÓGICAS DA COMPETITIVIDADE ATRAVÉS DAS PESSOAS
}

\author{
Miguel Pina e Cunha*
}

Jorge F. Gomes*

Este artigo desenvolve-se em torno da ideia de que a obtenção de vantagem competitiva, através das pessoas, implica uma gestão de recursos humanos fundada em filosofias de gestão de pessoal capazes de potenciar as capacidades individuais. Tais filosofias obrigam, por sua vez, ao reconhecimento das bases psicológicas do comportamento organizacional. Nesse sentido, este artigo procura: a) realçar a importância e a actualidade do trabalho de autores clássicos como Herzberg, McGregor e Argyris; $b$ ) destacar a importância de relações de trabalho cooperativas em vez de adversativas; e $c$ ) discutir a potencial contribuição de toda uma constelação de técnicas de gestão de recursos humanos, para a obtenção de vantagem competitiva sustentada através das pessoas.

\section{DO HOMEM ORGANIZACIONAL...}

Uma das preocupações centrais das ciências organizacionais contemporâneas tem a ver com a análise das fontes de vantagem competitiva, quer das nações quer das organizações empresariais. O trabalho de Michael Porter neste domínio é sobejamente conhecido, tendo o autor inclusive aplicado o x'u modelo de análise à economia portuguesa (Porter, 1994). 
Nesse modelo, Porter refere os seguintes factores como estando na base da competitividade: entrada de novos concorrentes, ameaça de substitutos, poder negocial dos compradores, poder negocial dos fornecedores e a rivalidade existente entre os concorrentes (Porter, 1985).

A nova envolvente de negócios - global (Oviatt \& McDougall, 1995), hipercompetitiva (D'Aveni, 1994), de alta velocidade (Eisenhardt, 1989) -, tendo na informação o seu recurso crítico, desenha toda uma nova série de oportunidades e desafios de gestão (Taillieu, 1996), ao mesmo tempo que promove uma "nova" fonte de competitividade. Essa fonte, mesmo tendo sido sempre uma componente importante da competitividade das empresas, pode de algum modo ser considerada uma "fonte oculta", tal é a menoridade que parece assumir em muitas empresas: as pessoas.

A relativa subalternização dos recursos humanos, em relação às outras possíveis fontes de vantagem competitiva, decorre do facto de a corrente dominante na gestão, ao longo do século, ter sido directa ou indirectamente modelada pelo pensamento de Frederick Winslow Taylor. Logo pelo princípio do século, Taylor (e.g. Taylor, 1911) defendeu uma "abordagem científica" da gestão, a qual preconizava um planeamento do trabalho tão rigoroso quanto possível, por forma a tornar as pessoas tão fiáveis e previsíveis como as máquinas com que essas pessoas trabalhavam. Nesse sentido, as tarefas deviam ser bem definidas, medidas e controladas, de tal forma que os respectivos executantes não introduzissem variações em relação ao previsto. É neste contexto que surge o conceito de homem organizacional (cf. Bartlett \& Ghoshal, 1995), feito à imagem da organização industrial, da linha de montagem e da metáfora mecanicista.

O modelo taylorista de separação entre o planeamento e a execução do trabalho sobreviveu até aos nossos dias. Não sendo abertamente aceite pela esmagadora maioria dos gestores contemporâneos, o taylorismo continua em todo o caso a vigorar sob diversas formas':

a) na simplificação do trabalho;

b) na aceitação dos pressupostos do homem económico;

c) na separação clara entre as componentes de planeamento e execução do trabalho;

d) na subalternização das capacidades das pessoas enquanto forças-motrizes de muitos resultados valorizados pela organização (produtividade, qualidade);

$e$ ) na popularidade de teorias organizacionais que têm por base modelos da natureza humana de valor discutível (vide a economia dos custos de transacção; e.g. Williamson \& Ouchi, 1981 e para uma crítica, Ghoshal \& Moran, 1996); 
f) nas resistências levantadas a modelos de gestão que impliquem, em maior ou menor grau, a partilha da capacidade de decisão.

Neste artigo, será apresentada argumentação favorável a uma gestão de recursos humanos que veja as pessoas como uma possível fonte de vantagem competitiva sustentável.

Defenderemos que a transformação das pessoas numa fonte de vantagem competitiva para a organização passa, antes de mais, pela compreensão das bases psicológicas do comportamento organizacional, da qual podem ser derivadas filosofias e técnicas de gestão compatíveis com o desenvolvimento das pessoas, o qual nos parece condição necessária (embora não suficiente) para o desenvolvimento da empresa.

Não se trata aqui de entender os recursos humanos como o princípio e o fim do sucesso das empresas, mas como, conforme os casos, uma fonte de construção ou de erosão (normalmente lenta e dificilmente perceptível) da competitividade das organizações. As pessoas não chegam para fazer o sucesso das empresas, mas sem empregados motivados e competentes, dificilmente uma organização será capaz de obter bons resultados a longo prazo. A competitividade empresarial deve ser entendida como residindo na articulação das diversas componentes organizacionais, de tal forma que elas se reforcem mutuamente e assim permitam a criação de sinergias. Dadas as premissas em que assenta, este artigo rompe com a filosofia de gestão de recursos humanos vigente em muitas empresas portuguesas: defende-se aqui que a gestão de pessoal não pode fundamentar-se na lógica da mão-de-obra barata nem na concepção do departamento de pessoal como o "parente pobre" dos departamentos organizacionais. Estes dois pontos de partida divergem do utilizado por muitas empresas, conforme se pode atestar em dois artigos de imprensa publicados num passado recente:

a) Segundo o semanário Expresso, e tendo por base um relatório do Departamento de Estatística do Ministério do Emprego e Segurança Social, as "PME querem mão-de-obra barata" ("Emprego", 26/8/95, p.1). No mesmo texto é constatado o aumento do recurso ao trabalho precário.

b) No número de Agosto de 1995 da revista Exame, uma peça sobre os "Caminhos que levam ao topo" alerta para o facto de "Em épocas de crise, o departamento de RH ser o primeiro a não recrutar” (p.123). Se a crise obriga as empresas a cortar no que é menos essencial, então esta constatação poderá conduzir à ideia de que há departamentos menos essenciais que outros, sendo um deles o departamento de recursos humanos. $O$ que faz sentido no caso de empresas que não entendam as pessoas como fonte de vantagem competitiva. 


\section{2. ...À ORGANIZAÇÃO HUMANA}

A emergência de uma sociedade pós-industrial tornou notória a necessidade de adoptar modelos de pensamento e de acção mais consentâneos com as necessidades de flexibilidade e de adaptação, que actualmente tendem a dominar as preocupações dos gestores. De uma lógica de sistema fechado, centrada nos processos de controlo e na rotinização dos mecanismos produtivos, as organizações passaram a ver-se confrontadas com a necessidade de recorrer a uma lógica de sistema aberto, genuinamente atenta à envolvente e à necessidade de adaptação permanente. Nesta lógica, ganharam relevância actividades como a inovação e a aprendizagem organizacionais, bem como técnicas desenvolvidas com vista a auxiliar a organização a aprender ("benchmarking") ou a libertar-se de processos inúteis e inibidores, quer da eficiência quer da capacidade de adaptação (reengenharia).

Todo este processo de transformação das organizações e da envolvente tem obrigado a prestar maior atenção às pessoas. Bartlett e Ghoshal (1995), por exemplo, defendem que o principal papel que aos gestores de topo cabe desempenhar passa pela individualização das empresas, da qual dependerá a capacidade de melhorar a utilização das potencialidades dos recursos humanos.

A humanização das organizações é, de resto, cada vez mais defendida como um passo essencial para a sua sobrevivência. Este movimento no sentido da humanização não seria por isso consequência de uma qualquer filosofia ingénua de gestão, mas antes o reconhecimento de que o deficiente aproveitamento das capacidades das pessoas é, em si mesmo, uma fonte não desprezível de perda de eficiência. A prazo, e numa sociedade em que o serviço é cada vez mais importante (Marques \& Cunha, 1995), esse mau aproveitamento acabará quase inevitavelmente por se reflectir na erosão da base de recursos e, por conseguinte, na fragilização da posição competitiva da empresa.

Os argumentos centrais deste artigo, que a seguir se desenvolverão, defendem que a humanização das organizações: $a$ ) é, no actual contexto de negócio, uma necessidade e que $b$ ) a humanização das organizações depende de $b 1$ ) uma compreensão correcta da natureza humana e das bases psicológicas do comportamento organizacional, e da $b 2$ ) aplicação ajustada e assente numa filosofia de gestão compatível, de um conjunto de técnicas de gestão e desenvolvimento sustentado das pessoas e da organização.

Não se pretende aqui encaminhar a argumentação para uma "one best way" que tudo reduz à gestão de pessoal assente na filosofia e nos princípios enunciados: com efeito, se os resultados perseguidos são de curto prazo e se a organização não está genuinamente interessada na implicação e na permanência dos seus trabalhadores, outras políticas, baseadas noutras filosofias, poderão ser aconselháveis. As cadeias de restaurantes de fast food, por exemplo, estão normalmente 
mais interessadas em promover altos níveis de turnover do que em garantir aos seus empregados funções motivadoras e um ambiente de trabalho estimulante.

\section{AS BASES PSICOLÓGICAS DO COMPORTAMENTO ORGANIZACIONAL}

Gerir as pessoas, como fonte de vantagem competitiva, implica antes de mais uma compreensão adequada da natureza do comportamento humano em contexto organizacional. Esta necessidade, já apontada por McGregor em 1960, continua por satisfazer no caso de muitas empresas contemporâneas. $\mathrm{O}$ que significa que as pessoas são geridas tendo por base pressuposições incorrectas, as quais, por influência de mecanismos de auto-realização de profecias, acabam por cristalizar e por ser tomadas como válidas.

Vale a pena retomar a argumentação de Douglas McGregor no seu clássico The Human Side of Enterprise, no que se refere à influência das pressuposições sobre a natureza humana ao nível da gestão do comportamento organizacional:

Há uma outra ilusão que se revela muito comum nas tentativas da direç̧ão para controlar o comportamento humano. Quando não alcançamos os resultados desejados, tendemos a procurar as causas do fracasso por toda a parte menos onde elas normalmente estão: na nossa escolha de métodos de controlo inadequados. $O$ engenheiro não põe a culpa na água por correr para baixo em vez de correr para cima, nem acusa os gases de se expandirem em vez de se contraírem quando aquecidos. No entanto, quando as pessoas reagem às decisões administrativas de maneira não desejada, a resposta natural é acusá-las. A sua estupidez, a sua falta de cooperação, ou a sua preguiça é que são apontadas como causa do que aconteceu, $\mathrm{e}$ não a omissão da administração na selecção de meios adequados de controlo (McGregor, 1960, p. 21).

A longevidade de concepções próximas do modelo do "homem económico" e a derivação de técnicas de gestão a partir desse modelo não deixam de ser surpreendentes, se se considerarem os ensinamentos de duas das teorias mais firmemente estabelecidas no domínio do comportamento organizacional (a teoria motivação-higiene, de Herzberg e a teoria Y, de McGregor) e de um tópico em crescendo de importância, a aprendizagem organizacional. Nas secções que se seguem proceder-se-á a uma apresentação sumária dos traços principais destas duas abordagens e procurar-se-á ilustrar a importância do conhecimento das bases psicológicas do comportamento organizacional, para uma gestão de recursos humanos capaz de fazer das pessoas uma fonte autêntica de vantagem competitiva e de aprendizagem contínua. Máximas tantas vezes apregoadas, do género "as pessoas são o nosso maior activo", só fazem sentido se a organização gerir as pessoas de acordo com as características da natureza humana, em vez de pretender adaptar a natureza humana à índole da organização. Quando esta segunda forma de actuação prevalece, assiste-se a um lote de comportamentos defensivos que 
incluem a fuga dissimulada aos mecanismos de controlo da organização, a diminuição deliberada do ritmo de trabalho, os protestos activos (conflitos) ou passivos (desimplicação), as pressões grupais no sentido de objectivos não necessariamente congruentes com os da organização.

\subsection{As Teorias X e Y, de McGregor}

A formulação, por Douglas McGregor (1960), dos princípios das teorias X e $\mathrm{Y}$, nasce da tentativa de desocultação das pressuposições subjacentes às práticas de gestão de pessoal. No seu livro The human side of entreprise, McGregor apresentou as teorias $\mathrm{X}$ e Y, a primeira descrita como "a concepção tradicional de direcção e controlo", a segunda como "administração por integração e autocontrolo".

A Teoria $\mathrm{X}$ baseia-se em pressuposições como as seguintes (retiradas da referida obra):

a) O ser humano, de um modo geral, tem aversão essencial ao trabalho e evitao sempre que possível;

b) Devido a essa característica humana de aversão ao trabalho, a maioria das pessoas precisa de ser coagida, controlada, dirigida e ameaçada de punição, para que se esforce no sentido da consecução dos objectivos organizacionais;

c) O ser humano, de modo geral, prefere ser dirigido, quer evitar responsabilidade e tem relativamente pouca ambição.

Embora a maioria das pessoas não se reveja neste conjunto de pressupostos, a verdade é que é neles que continua a ser baseada a gestão de pessoal de muitas empresas. Este conjunto, potencialmente erróneo, de suposições acerca da natureza humana, conduz inevitavelmente a práticas de gestão baseadas no controlo e a relações laborais de tipo adversativo. Dado o conjunto de desafios que as actuais condições competitivas colocam às organizações (e.g. Kanter 1986), este lote de princípios tende a surgir como disfuncional se o objectivo da organização é o de conseguir transformar o seu pessoal, de forma sólida e numa perspectiva de longo prazo, numa fonte de vantagem competitiva. Daí que surjam como mais ajustados os princípios enunciados pela Teoria $\mathrm{Y}$ :

a) O dispêndio de esforço físico e mental no trabalho é tão natural como o jogo ou o descanso;

b) O controlo externo e a ameaça de punição não são os únicos meios de estimular o trabalho tendo em vista os objectivos organizacionais; 
c) O compromisso com os objectivos é dependente das recompensas associadas à sua consecução;

d) O ser humano comum aprende, sob condições adequadas, não só a aceitar responsabilidades como a procurá-las;

e) A capacidade de usar um grau relativamente alto de imaginação, de engenhosidade e de criatividade na resolução dos problemas organizacionais é mais amplamente distribuída na população do que geralmente se pensa;

f) Nas condições da vida industrial moderna, as potencialidades intelectuais do ser humano comum estão apenas a ser parcialmente usadas.

As pressuposições da Teoria $\mathrm{Y}$, indiciando o potencial de crescimento e de desenvolvimento humano, fundamentam a possibilidade de desenvolver políticas de gestão de pessoal baseadas na cooperação, na aprendizagem e no desenvolvimento sustentado e de longo prazo dos indivíduos e das organizações, radicalmente diferentes das preconizadas pela Teoria $\mathrm{X}$.

\subsection{A Teoria Motivação-Higiene, de Herzberg}

A teoria motivação-higiene (TMH), de Herzberg, constitui uma das perspectivas mais conhecidas no domínio da psicologia do trabalho. Trata-se de uma abordagem construída com base na análise de incidentes críticos no local de trabalho e desenvolvida com vista a proporcionar uma explicação da natureza e das necessidades humanas.

Em termos simples pode dizer-se que a TMH afirma a existência de dois tipos de necessidades, higiénicas e motivacionais, que operam de forma independente e obedecendo a diferentes dinâmicas (para uma análise mais detalhada deste teoria, ver Herzberg, 1996). A TMH vem alertando para o facto de estas dinâmicas serem muitas vezes confundidas, o que conduz a modelos de gestão baseados no equívoco de que satisfação e motivação são uma e a mesma coisa. Este equívoco, que sobrevive até aos dias de hoje, resulta depois na implementação de políticas de gestão de pessoal erróneas porque baseadas em pressupostos incorrectos. $\mathrm{O}$ ciclo de equívocos, que frequentemente decorre da concepção inadequada das bases do comportamento organizacional, dá sentido a uma afirmação de Kohn (1993) que, em determinados contextos, pode parecer enigmática: "prometer uma recompensa a alguém que se sente desmotivado é um pouco como oferecer água salgada a alguém que tem sede". A TMH pode ajudar a perceber porquê.

Os factores motivadores (aqueles que dizem respeito ao trabalho em si mesmo) são os responsáveis pela existência ou não de satisfação. Os factores higiénicos (aqueles que dizem respeito à envolvente de execução do trabalho) são responsáveis pela existência ou não de insatisfação. Satisfação e insatisfação 
seriam, como tal. resultados de trabalhos diversonc clevidos a causas distintas, isto é, as causas da satisfação não são as causas da insalistação.

Pese embora alyuma confusão conceptual entre as variáveis motivação e satisfação, a TMH conduı a uma verificação de importância crucial: os factores exteriores ao trabalho podem contribuir para mitigar a insatisfação mas não conduzem à satisfação. A satisfação, para usarmos a nomenclatura de Herzberg, seria função da presença ou ausência dos factores motivadores. $O$ que significa que, se se pretende aumentar a satisfação dos trabalhadores, é preciso actuar ao nível do trabalho em si mesmo e não ao nível dos factores exteriores/higiénicos, como o salário, as condições de trabalho, as relações interpessoais, etc. A afirmação de Kohn, acima citada, pode agora ser entendida com alguma clareza: as organizações tendem, muitas vezes, a procurar estimular a motivação usando factores higiénicos, o que à luz da TMH é errado.

Enquanto numa empresa persistir a confusão entre gestão da satisfação e gestão da motivação, dificilmente a gestão de pessoal poderá corresponder às necessidades, quer das pessoas quer da organização. A razão para que tal aconteça, lida de acordo com a formulação de Herzberg, é fácil de entender: sendo o diagnóstico errado, a cura não pode ser adequada.

As práticas de gestão de pessoal baseadas nos factores higiénicos não podem, por conseguinte, originar os resultados esperados. Em muitas empresas, a gestão de pessoal centra-se, contudo, neste tipo de factores, manifestando-se em práticas do estilo "pontapé nos fundilhos" (Herzberg, 1996) ou na administração da higiene compensatória, ao invés de se desenvolver em torno do enriquecimento do trabalho, da responsabilidade e da aprendizagem e crescimento dos trabalhadores.

\subsection{A aprendizagem humana nas organizações}

As abordagens teóricas da aprendizagem assentam as suas raízes na investigação psicológica. Conceitos como os de condicionamento clássico ou condicionamento operante têm já décadas de existência e a sua aplicação, à modificação do comportamento humano, é prática corrente em contexto organizacional.

Nos últimos anos, a aprendizagem tem merecido um amplo destaque na literatura de gestão. A razão para tanta saliência radica no facto de a aprendizagem vir sendo apontada como um dos processos que permitem o "salto para a frente", ou seja, para a evolução no sentido da organização competitiva.

Particularmente importante, no quadro da aprendizagem organizacional, é o trabalho de Chris Argyris, que considera (e.g. Argyris, 1976, 1994) duas formas de aprendizagem em ambiente de trabalho: aprendizagem adaptativa ou de single loop, e aprendizagem generativa, ou de double loop. Em termos muito sintéticos, dir-se-ia que a primeira corresponde a uma resposta simples a uma pergunta sim- 
ples, ao passo que a segunda implica o questionamento dos procedimentos, das normas e das regras existentes.

A aprendizagem em double loop implica uma análise profundal dos problemas e o questionamento das decisões tomadas. Ao serem promovidas. cstas análises abrem o caminho para a verdadeira aprendizagem e, consequentemente, para a renovação da organização no longo prazo.

Tradicionalmente, as organizações tendem a optar pela aprendiziggem em single loop, adoptando práticas de gestão inibidoras da verdadeira compreensão dos factos. O questionamento é desencorajado por razões de duas ordens: $a$ ) a força dos procedimentos existentes, e $b$ ) o carácter defensivo dos comportamentos prevalecentes em muitas organizações. Neste último caso, os indivíduos utilizam determinado tipo de estratégias cognitivas defensivas, para analisar situações e resolver problemas. Procuram deste modo evitar a vulnerabilidade causada pelo risco, pelo embaraço e pela aparência de incompetência. Este raciocínio defensivo constituirá um dos pilares fundamentais da anti-aprendizagem. No primeiro caso - a força dos procedimentos instituídos -, a organização constrói políticas, práticas e acções, que obstam ao questionamento dos comportamentos exibidos e a uma análise aprofundada das razões subjacentes às decisões dos actores organizacionais. Estas políticas, práticas e acções, tendem a desencorajar a reflexão e a ceifar a curiosidade humana, constituindo deste modo uma força de anti-aprendizagem.

Do que se expôs, decorre que os comportamentos organizacionais podem tornar-se cristalizados não apenas devido a factores intrínsecos ao homem, mas também a factores contextuais, como a estrutura, as práticas de contratação e de promoção, os sistemas de recompensa, etc. A incapacidade manifestada por muitas organizações em termos da implementação de sistemas de aprendizagem generativa radica, antes de mais, numa concepção desfocada da natureza humana, herdada dos modelos do "homem económico" e pouco ajustada às necessidades competitivas das organizações contemporâneas. Envolventes de alta-intensidade concorrencial sugerem a necessidade de desenvolver nas organizações a capacidade de aprender a aprender, assim se estabelecendo a articulação entre as teorizações de Herzberg, McGregor e Argyris.

Dado o estado de coisas até aqui apresentado, que razões têm obstado a uma penetração mais significativa da psicologia nas organizações? Na seç̧ão que se segue, procurar-se-á avançar alguns argumentos.

\section{OBSTÁCULOS À DIFUSÃ() DAS TEORIAS PSICOLÓGICAS}

Tendo as abordagens de Her/berg e de McGregor sido desenvolvidas nos anos 60 , porque razão nầ punciratram elas de forma mais profunda o pensamento 
e a prática da gestão de empresas? Sem pretender esgotar o tema, apresentamos a seguir algumas tentativas de resposta:

a) Pese embora a aceitação "superficial" destas teorias, a sua passagem à prática tem sido obstruída por um conhecimento insuficiente das técnicas necessárias para traduzir estas teorias da natureza humana em práticas adequadas de gestão de pessoal;

b) Mesmo admitindo que se trata de teorias "muito bonitas no papel", muitos gestores consideram, a priori, que elas não se aplicam à sua organização. $\mathbf{O}$ leque de razões apontadas para esta inadequação é bastante diverso (indo, alegadamente, da falta de capacidades à falta de motivação dos seus trabalhadores) mas, a avaliar pela experiência subjectiva dos autores, trata-se de um conjunto de "motivos" generosamente distribuído pela comunidade empresarial. Esta atitude de "aceitação teórica e rejeição prática" pode por sua vez decorrer de, pelo menos, duas causas, que a seguir se apresentam;

c) Académicos e gestores parecem desenvolver quadros de referência distintos, os quais dificultam a comunicação entre a universidade e a empresa. Esses diferentes quadros de referência tendem a resultar no desenvolvimento de conceitos diversos sobre a natureza e o funcionamento das organizações, o que conduz ao desenvolvimento de diferentes metáforas sobre as mesmas. As organizações são muitas vezes descritas pelos gestores com base em metáforas com conotações bélicas (recrutamento de pessoal, definição da missão, estratégia competitiva, marketing de guerrilha, guerra de preços ou de marcas), ao passo que os académicos recorrem frequentemente a metáforas de carácter não-bélico, tais como estruturas orgânicas, burocracias mecanicistas, sistemas de aprendizagem, hologramas, etc. (Shrivastava \& Mitroff, 1984);

d) Os diferentes quadros de referência tendem, por seu turno, a resultar em diferentes filosofias de gestão. Dada a predominância, junto dos práticos, das imagens da gestão enquanto "guerra" pela sobrevivência, pelo lucro e pelas quotas de mercado, torna-se por vezes difícil, mesmo a nível interno, desenvolver filosofias de gestão baseadas na cooperação. Se a este grupo de factores juntarmos a desconfiança de algumas teorias, relativamente à índole da natureza humana (caso da já referida economia dos custos de transacção) e o poder da confirmação de expectativas, concluiremos que existe, tacitamente e em termos de fílosofia de gestão, um viés no sentido do conflito. Este viés torna praticamente impossível fazer das pessoas uma fonte de vantagem competitiva para a organização. Este quadro não deixa de ser intrigante se se atender ao facto de a investigação mostrar que as dinâmicas de cooperação tendem a facilitar a interacção social e a produtividade (Tjosvold, 1984). 
Como se procurou ilustrar nesta secção, uma gestão de pessoal voltada para o desenvolvimento mútuo das pessoas e da organização deve decorrer: $a$ ) em primeiro lugar, de um conhecimento adequado sobre a natureza do comportamento humano nas organizações e, $b$ ) em segundo lugar, da implementação de processos de gestão das pessoas concordantes com essa mesma filosofia e capazes de a traduzir em termos práticos.

Na próxima secção, serão apresentadas algumas dessas técnicas. Desde já alertamos para o facto de essas técnicas, por si sós, não serem boas nem más. Os seus resultados dependem sobretudo da filosofia em que se enquadram e que devem supostamente apoiar. Convém igualmente referir que a constelação de técnicas que será apresentada não deve ser lida como uma receita de culinária: há técnicas que fazem sentido em determinadas situações mas não noutras, pelo que a sua aplicação deve decorrer das necessidades da organização e não dos modismos aos quais a gestão em geral e a gestão de pessoal em particular são muito atreitas (Abrahamson, 1996).

\section{UMA CONSTELAÇÃO DE TÉCNICAS DE GESTÃO PARA A CRIAÇÃO DA ORGANIZAÇÃO HUMANA}

No seu estudo já clássico, de 1960, Douglas McGregor defende a certa altura (p.60) que a Teoria Y é um convite à inovação. Vinte e cinco anos depois, a Teoria $\mathrm{Y}$ continua, para a maioria das empresas, a ser um convite à inovação. $\mathrm{O}$ argumento central deste artigo defende que o sucesso da gestão de pessoal passa, antes de mais, pela compreensão das bases psicológicas do comportamento organizacional. Esta compreensão, aliada ao reconhecimento de que os "recursos humanos" podem ser tratados como um activo a desenvolver (em vez de, como habitualmente, serem entendidos como um custo a reduzir), traduzir-se-á provavelmente numa dramática mudança de registo da gestão de pessoal (ver Bartlett \& Ghoshal, 1994). Essa mudança de registo (ou de filosofia) fará sentido se a organização pretender:

a) obter vantagem competitiva através das pessoas e numa perspectiva de longo prazo;

b) ter pessoas que desenvolvam um sentimento de pertença em relação à organização ou empregados que trabalham para a empresa (esta é, segundo Bartlett \& Ghoshal, 1994, a diferença entre contratar um mercenário ou formar um fuzileiro).

Se o objectivo de uma organização é o de criar e de sustentar, a longo prazo, a sua vantagem competitiva através das pessoas (isto é, se os empregados podem 
fazer a diferença em relação à concorrência através da sua motivação, implicação, capacidade e vontade de aprendizagem, potencial de desenvolvimento e contributos para a inovação), ela deverá desenvolver uma filosofia de gestão de pessoal baseada nos princípios acima referidos e apoiada por um conjunto de técnicas de gestão que só têm utilidade se emanarem, como dissemos, de uma filosofia de gestão que as integre num propósito organizacional (sobre o tema ver Caldeira, 1996), com significado para os trabalhadores. As técnicas que a seguir vão referir-se, não são, em si mesmas, boas ou más: a sua riqueza e eficácia dependem principalmente da sua concordância com a filosofia de gestão que lhes subjaz; estas técnicas ou reforçam a filosofia de gestão de pessoal, ou não passam de exercícios demagógicos de mudança, semeados em solo adverso (um exemplo: não vale a pena ensaiar técnicas que implicam a descentralização do poder e da capacidade de decisão, como o empowerment, se a gestão de topo não pretende, de facto, abdicar de uma gestão centralizada).

Defende-se aqui que a motivação deverá ser entendida, no actual estado do conhecimento, como a variável central de qualquer modelo de gestão de pessoal. Esta posição baseia-se em dois tipos de argumentos: (1) o reconhecimento da validade empírica das teorias da motivação (cf. Marques, 1995; Miner, 1984); (2) o papel crucial da motivação nos resultados humanos e produtivos do trabalho, sustentado empiricamente por um extenso volume de investigação (e.g. Locke \& Latham, 1991; Hackman \& Oldham, 1980). Especialmente relevante é, neste quadro, a defesa da importância da motivação intrínseca (e.g. Ryan, Mims \& Koestner, 1983), um conceito infelizmente mal conhecido fora das escolas de psicologia: os trabalhadores devem ser motivados pelo trabalho em si mesmo e sentir-se psicologicamente implicados com a organização. $O$ uso de motivadores extrínsecos deve ser usado com adequação, sob pena de ameaçar a permanência da motivação intrínseca.

Não se trata aqui de pôr em causa a importância dos motivadores extrínsecos (e designadamente as recompensas, a sua variante mais conhecida), mas simplesmente de os situar num quadro de gestão que promova o desenvolvimento dos recursos humanos, tendo por base o conhecimento disponível sobre a natureza profunda do comportamento organizacional. Não se pretende com isto psicologizar a gestão mas simplesmente usar as ferramentas conceptuais proporcionadas pela psicologia do trabalho e das organizações, colocando-as ao serviço das empresas e, simultaneamente, daqueles que nelas trabalham. A premissa subjacente a este tipo de filosofia é a de que o desenvolvimento das organizações é inseparável do desenvolvimento das pessoas.

Para promover o desenvolvimento simultâneo de pessoas e organizações, apresentam-se a seguir algumas técnicas que podem ser usadas para transformar as pessoas numa fonte de vantagem competitiva sustentada. De acordo com Pfef170 fer (1994), são os seguintes os benefícios da vantagem competitiva através das 
pessoas: a) a empresa, através das suas práticas de gestão de pessoal, diferenciase da concorrência, $b$ ) obtém benefícios económicos, e $c$ ) desenvolve uma fonte de vantagem muito difícil de copiar.

\section{Uma constelação de técnicas de gestão para a obtenção de vantagem competitiva através das pessoas}

Selecção. Se uma organização pretende ter nas pessoas uma fonte de vantagem competitiva, a primeira coisa que ela tem a fazer consiste em desenvolver sistemas de selecção adequados. Quando aqui se fala num sistema adequado pretende-se significar um sistema apertado e rigoroso. Esse rigor depende de pelo menos dois factores: da qualidade dos métodos de seleç̧ão usados (para uma panorâmica portuguesa, ver Ribeiro, 1996) e da existência de perspectivas claras, por parte da organização sobre aquilo que se espera das pessoas. As expectativas em relação aos novos colaboradores devem referir-se não apenas às suas capacidades cognitivas, mas também a um conjunto de aspectos psicológicos, como os valores e motivações individuais e a vontade de aprender. A vantagem competitiva através das pessoas começa por se definir no conjunto de indivíduos que se juntam aos quadros da organização.

Antevisão realista da função. Para cativarem os candidatos interessantes, algumas organizações optam por vezes por lhes apresentar as funções em tons mais positivos que os reais. Este "brilho acrescentado" é todavia mais nefasto do que positivo, criando sentimentos de desmotivação e eventualmente de revolta nos candidatos. A antevisão realista da função não parece provocar níveis de desistência superiores aos normais e prepara o candidato para a função que, de facto, lhe vai caber desempenhar, evitando criar expectativas superiores à realidade. Para lá de evitar a criação de "insuficiências motivacionais", a antevisão realista da função contribui para a instalação de um estado de confiança recíproca entre a empresa e o trabalhador, condição essencial para a construção de vantagem competitiva através das pessoas.

Reestruturação de funções. Se a motivação decorre fundamentalmente do trabalho desenvolvido, o potencial motivacional do trabalho tem que ser objecto de particular atenção. Funções repetitivas, pobres e monótonas, não proporcionam normalmente níveis de motivação suficientes para que as pessoas possam estar na base de quaisquer ganhos competitivos. $\mathrm{O}$ modelo das características da função (Hackman \& Oldham, 1980) constitui um ponto de partida válido para a análise e reestruturação de funções.

Gestão de salários. Se uma empresa pretende chamar e fixar bons empregados, tem que lhes pagar salários concordantes com o seu valor. Os salários baixos 
começam desde logo por desmotivar os bons candidatos no momento da selecção e, a prazo, criarão condições para que os melhores colaboradores sejam cobiçados e aceitem transferir-se para a concorrência por razões salariais. Sabe-se que um bom salário não é, só por si, um motivador, mas também se sabe que um salário baixo é fonte de insatisfação. $O$ baixo custo da mão-de-obra só deverá ser entendido como factor de competitividade pelas empresas que não disponham de quaisquer outras fontes de vantagem. Uma forma de mostrar às pessoas que elas são importantes e que a empresa espera muito delas passa pela valorização do seu salário. A necessidade de achatamento das pirâmides organizacionais ou a adopção de estruturas, não construídas com base no factor hierárquico, leva algumas organizações a optar por novas políticas de gestão de salários. A compressão salarial, por exemplo, é já uma política em uso. Formas de partilha de lucros e de participação dos empregados no capital da empresa constituem alternativas à cada vez maior dificuldade em continuar a fazer a gestão de salários com base em esquemas associados à progressão (hierárquica) na carreira.

Gestão das recompensas. Se os colaboradores são fonte de criação de riqueza, devem ser recompensados pela sua acção. Para poder ser eficaz, a gestão de recompensas deve ter sempre presente a diferença entre motivação intrínseca e extrínseca e entre factores motivadores e higiénicos, isto é, as recompensas devem ser vistas como uma consequência da actividade desenvolvida e não como uma forma de tornar mais tolerável e desafiante um trabalho maçador ou sem significado. Segundo Pfeffer (1994), a gestão de recompensas deverá obedecer aos seguintes critérios: os lucros da empresa, confiança, qualidade, resultados, ideias e cooperação. Para evitar o desenvolvimento de rivalidade intra-organizacional e a consequente substituição de uma lógica de colaboração por outra de competição, podem ser usadas técnicas como os programas de repartição de lucros e a recompensa de equipas em vez das recompensas individuais.

Empowerment. A recente popularidade do empowerment recoloca na ordem do dia a importância da participação dos empregados. A investigação sobre a participação deu origem a resultados contraditórios, mas coloca-se aqui a hipótese de muita dessa investigação ter procurado encontrar uma relação de causalidade onde ela provavelmente não existe: entre participação e produtividade. $\mathrm{O}$ empowerment, em si mesmo, não deverá por isso ser entendido como fonte directa de produtividade. A sua importância decorre sobretudo do facto de libertar informação e capacidade de decisão para a base, e de assim tornar possível a melhoria do conteúdo motivacional da função (ver Hackman \& Oldham, 1980) e de, ao mesmo tempo, desde que correctamente gerido, criar condições para aumentar a capacidade de resposta imediata às 
solicitações dos clientes, facto especialmente importante para a organização de serviços.

Grupos. Os grupos formam um elo entre o indivíduo e a organização: esta afirmação vulgarizou-se ao ponto de normalmente se perder a noção das suas potencialidades. A organização, através da implementação de uma estrutura, assegura coordenação e controlo sobre os comportamentos individuais. A responsabilidade por estes resultados pode todavia ser transferida para os grupos, sem perda das vantagens e com a remoção de um inconveniente: o controlo pelo grupo pode assumir muito maior subtileza e garantir aos empregados uma percepção de autonomia que é importante para a construção social da função motivadora.

Formação/aprendizagem/desenvolvimento. A obtenção de vantagem competitiva pelas pessoas implica a necessidade de actualizar, em permanência, as capacidades de aprendizagem e de utilização do conhecimento pelos indivíduos. Se o desempenho pode ser entendido como função das capacidades e motivações, torna-se claro que não basta saber como motivar os empregados. É igualmente necesário saber como actualizar conhecimentos, de forma a que a organização actue como uma organização que aprende (Senge, 1990) ou como uma empresa capaz de criar conhecimento (Nonaka, 1991). Sem aprendizagem, partilha de informação e geração de conhecimento, as organizações estão a desperdiçar uma capacidade de renovação que, a prazo, poderá pôr em questão a sua própria sobrevivência, ou seja, a possibilidade de melhorar a sua focalização no mercado (Cunha, 1996).

Igualitarismo simbólico. A inspiração no modelo militar criou em muitas organizações estruturas e processos decalcados dos daquela instituição. Organizações fortemente hierarquizadas e com visíveis separações interníveis podem, contudo, não constituir a solução indicada quando se deseja que a organização funcione com base em modelos cooperativos, em vez de recorrer a modelos adversativos (sobre as soluções estruturais emergentes, ver Gomes, 1996). A existência de três salas de refeição, por exemplo, contribui para cavar distâncias entre níveis e para a criação de sentimentos do tipo "nós"/ "eles", bem conhecidos da psicologia social. Quando o objectivo é a cooperação, os símbolos desnecessários de diferenciação e de estatuto podem e devem ser eliminados. Com a ideia de igualitarismo simbólico não se pretende fazer passar qualquer tipo de mensagem ideológica "subliminar", nem defender a eliminação da hierarquia e da responsabilidade: pretende-se apenas eliminar formas de organização que, conduzindo à criação de fronteiras psicológicas e de "in" e "outgroups", promovem a competição tácita (e portanto não regulada) no interior da organização. 
Medição das práticas. Os resultados da gestão das pessoas devem ser medidos de forma quantitativa. Por duas razões: $a$ ) a medição permite obter indicadores objectivos que servem de base à redefinição das políticas de gestão de pessoal; $b$ ) a apresentação de medidas quantitativas é especialmente prezada em contextos de gestão que valorizam mais o quantitativo que o qualitativo. Uma das razões que leva as empresas a prestar pouca atenção aos aspectos da gestão de pessoal tem certamente a ver com o facto de em muitos casos a gestão de pessoal não ser traduzida em "números". Como os números mais visíveis se referem à massa salarial, uma das estratégias mais populares de gestão de pessoal passa pelo downsizing, que tem efeitos evidentes e de curto prazo ao nível dos custos. Se esta técnica é aplicada sem qualquer intenção estratégia que a suporte e justifique, o downsizing pode contudo ser visto como uma falsa solução que, se por um lado reduz custos, por outro pode diminuir ainda mais a competitividade da empresa, ao dizimar as redes sociais e ao eliminar os focos de redundância necessários para a aprendizagem e para a inovação organizacionais (Vansina \& Taillieu, 1996; Stacey, $1996^{2}$ ).

Antes de passar aos comentários finais, três notas breves relativamente às técnicas anteriores:

Filosofia de gestão. O sucesso da aplicação de qualquer das técnicas anteriormente referidas depende, antes de mais, da existência de uma filosofia de gestão congruente com o alcance de vantagem competitiva pelas pessoas;

Lentidão do processo. A obtenção de vantagem competitiva através das pessoas é um processo lento e delicado, baseado na confiança entre a gestão e os empregados, que pode facilmente ser posto em risco e que não é fácil de observar (da mesma maneira que, por exemplo, é fácil de observar uma suposta vantagem tecnológica no hardware tecnológico propriamente dito).

Carácter único. A vantagem competitiva pelas pessoas implica um esforço de longo prazo e não é visível no imediato mas, uma vez alcançada, torna-se difícil de imitar. O maior benefício da vantagem competitiva pelas pessoas assenta no facto de ela não se poder comprar, à semelhança por exemplo de uma nova tecnologia: o seu carácter é único e intransferível.

Visão sistémica. Mais do que um conjunto de práticas isoladas, as técnicas referidas devem ser integradas num modelo abrangente e sistémico, que entenda filosofias e práticas como elementos complementares de um único sistema (vide Huselid, 1995). O que desaconselha que se espere demasiado desta ou daquela "prática milagrosa", seja ela qual for e por mais sedutor que seja o "embrulho". 


\section{COMENTÁRIOS FINAIS}

A literatura recente na área da gestão tem vindo a dedicar uma atenção redobrada ao lado humano da organização, entendendo-a não apenas como um local de produção mas como um espaço social de trabalho, cujos resultados dependem em boa medida da forma como esse espaço social é concebido e gerido.

A importância do lado humano da organização, reconhecida desde os estudos de Hawthorne, tem sido talvez mais discutida do que passada à prática. O impacto de trabalhos, como o livro mais recente de Jeffrey Pfeffer (1994) ou a trilogia de artigos de Bartlett e Ghoshal para a Harvard Business Review (1994, 1995, Ghoshal \& Bartlett 1995), poderá contudo contribuir para que o lado soft da gestão receba a atenção que aparentemente merece. Trata-se, no fundo, de equilibrar a componente hard (estratégia-estrutura-sistemas) com uma vertente que, por ser mais "mole", talvez não pareça tão adequada à visão heróica da gestão muitas vezes transmitida nas business schools e na literatura das ciências da organização. Sem negar a importância do triângulo duro estratégia-estrutura-sistemas, defendeu-se aqui a necessidade de o complementar com o triângulo mole propósito-processo-pessoas, defendido por Bartlett e Ghoshal nos já referidos artigos.

Embora o lado duro das organizações represente uma componente essencial da gestão de empresas, ele não é $a$ gestão. Gerir é articular de forma harmoniosa e contingente o tríptico estratégia-estrutura-sistemas, mas é também entender as organizações como construções sociais, cujo sucesso pode ser inibido por uma compreensão insuficiente da respectiva componente humana. Esta recomendação, sendo porventura mais actual que nunca, está longe de ser uma novidade: tanto os trabalhos clássicos da escola sociotécnica (Trist, 1981) como os seus desenvolvimentos recentes (Correia, 1995) se desenvolvem em torno desta questão. Como refere Zald (1993), as organizações são instrumentos de criação de produtos e lucros, mas nem por isso deixam de ser locais de interacção humana, os quais, consoante a forma como são geridos, tanto podem ser fonte de crescimento e de desenvolvimento pessoal, como factores de frustração e de definhamento das capacidades individuais.

A perspectiva que aqui se apresentou parte do simples princípio de que, se forem entendidas como fontes de desenvolvimento das pessoas, as organizações contemporâneas poderão também ser fontes de maiores lucros, de melhores produtos e de uma conduta eticamente mais responsável. 


\section{NOTAS}

1 A ideologia de controlo do tipo racionalista, advogada pelo taylorismo, tem dominado a cena da ciência organizacional, em regime de alternância com a filosofia normativa, típica por exemplo da escola das relações humanas (Barley \& Kunda, 1992). Dada a sucessão de vagas racionalistas e normativas, não surpreende que as ideias de Taylor sejam regularmente repescadas, pelo que, em rigor, não é possível falar de uma rejeição do taylorismo nesta ou naquela época (vide também Hodgetts \& Greenwood, 1997).

2 Ver também Gould (1993, capítulo 7).

\section{BIBLIOGRAFIA}

ABRAHAMSON, E. (1996), "Management fashion". Academy of Management Review, 21, 254-285.

BARLEY, S. R. \& KUNDA, G. (1992), "Design and devotion: Surges of rational and normative ideologies of control in managerial discourse", Admninistrative Science Quarterly, 37, 363-399.

BARTLETT, C. A. \& Ghoshal, S. (1994), "Changing the role of top management: beyond strategy to purpose", Harvard Business Review, November-December, 79-88.

BARTLETT, C. A. \& Ghoshal, S. (1995), "Changing the role of top management: beyond systems to people", Harvard Business Review, May-June, 132-142.

CALDEIRA, P. Z. (1996), "Modelos mentais do estratega", in C. A. Marques \& M. P. Cunha (Eds.), Determinantes da gestão e relação com o mercado (pp.81-109), Lisboa, Dom Quixote.

CORREIA, M. F. (1995), "Tecnologias avançadas de produção e gestão das pessoas", Comportamento Organizacional e Gestão, 1, 265-284.

CUNHA, M. P. (1996), Recursos humanos e inovação organizacional: Para uma gestão focalizada no mercado (Manuscrito não publicado).

D'AVENI, R. A. (1994), Hypercompetition, New York, Free Press.

EISENHARDT, K. M. (1989), "Making fast strategic decisions in high velocity environments", Academy of Management Journal, 32, 543-576.

GHOSHAL, S. \& BARTLETT, C. A. (1995), "Changing the role of top management: beyond structure to process", Harvard Business Review, January-February, 86-96.

GHOSHAL, S. \& MORAN, P. (1996), "Bad for practice: A critique of the transaction cost theory", Academy of Management Review, 21, 13-47.

GOMES, J. F. (1996), "Estruturas para a informação: tecnologias de informação, sistemas de informação e design organizacional", in C. A. Marques \& M. P. Cunha (Eds.), Determinantes da gestão e relação com o mercado (pp.159-191), Lisboa, Dom Quixote.

GOULD, S. J. (1993), Eight little piggies, Edição portuguesa: Os oito porquinhos, Mem-Martins-Europa-América, 1996.

176 HACKMAN, J. R. \& OLDHAM, G. R. (1980), Work redesign, New York: Addison-Wesley. 
HERZBERG, F. (1996), “A teoria motivação-higiene”, in C. A. Marques \& M. P. Cunha (Eds.), Comportamento organizacional e gestão de empresas (pp. 43-65), Lisboa, Dom Quixote.

HODGETTS, R. M. \& GREENWOOD, R. (1997), "Frederick Taylor: Vivo e bem preparado para o séc.XXI", Comportamento Organizacional e Gestão, 3, 213-225.

HUSELID, M. A. (1995), "The impact of human resource management practices on turnover, productivity, and corporate financial performance", Academy of Management Journal, 38, 635-672.

KANTER, R. M. (1986), "The new workforce meets the changing workplace: strains, dilemmas, and contradictions in attempts to implement participative and entrepreneurial management", Human Resource Management, Winter, 515-537.

KOHN, A. (1993), "Why incentive plans cannot work". Harvard Business Review, September-October, 54-63.

LOCKE, E. A. \& LATHAM, G. P. (1990), A theory of goal setting and task performance, Englewood-Cliffs, Prentice-Hall.

MARQUES, C. A. (1995), "Impactos da gestão de pessoal no management", Comportamento Organizacional e Gestão, 1, 11-20.

MARQUES, C. A. \& CUNHA, M. P. (1995), A gestão de pessoal como factor-chave para a qualidade de serviço (relatório de investigação A-001), Oeiras, Metáfora.

McGREGOR, D. (1960), The human side of enterprise (Edição brasileira: O lado humano da empresa, São Paulo, Martins Fontes, 1980).

MINER, J. B. (1984), "The validity and usefulness of theories in an emerging organizational science", Academy of Management Review, 9, 296-306.

NONAKA, I. (1991), "The knowledge-creating company", Harvard Business Review, November-December, 96-104.

OVIATT, B. M. \& McDOUGALL, P. P. (1995), "Global start-ups: entrepreneurs on a worldwide stage", Academy of Management Executive, 9, 2, 30-44.

PFEFFER, J. (1994), Competitive advantage through people, Boston, Harvard Business School Press.

PORTER, M. E. (1985), Competitive advantage, New York, Free Press.

PORTER, M. E. (1994), Construir as vantagens competitivas de Portugal, Lisboa, Forum para a competitividade.

RIBEIRO, R. B. (1996), "Selecção de pessoal: Métodos e aplicações”, in C. A. Marques \& M. P. Cunha (Eds.), Comportamento organizacional e gestão de empresas (pp. 93-115), Lisboa, Dom Quixote.

RYAN, R. M., MIMS, V. \& KOESTNER, R. (1983), "Relation of reward contigency and interpersonal context to intrinsic motivation: a review and test using cognitive evaluation theory", Journal of Personality and Social Psychology, 45, 736-750.

SENGE, P. (1990), "The leader's new work: building learning organizations", Sloan Management Review, Fall, 7-23.

SHRIVASTAVA, P. \& MITROFF, I. I. ( 1984); "Enhancing organizational research utilization: the role of decision makers' assumptions", Academy of Management Review, 9, 18-26.

STACEY, R. D. (1996), "Criatividade nas organizações. A importância da desordem", Comportamento Organizacional e Gestão, 2, 5-23.

TAILLIEU, T. C. B. (1996), "Algumas tendências em organização e gestão", in C. A. Marques \& M. P. Cunha (Eds.), Determinantes da gestão e relação com o mercado (pp.325-388), Lisboa, Dom Quixote.

TAYLOR, F. W. (1911), The principles of scientific management, New York, W. W. Norton. TJOSVOLD, D. (1984), "Cooperation theory and organizations", Human Relations, 37, 743-767. 
TRIST, E. L. (1981), "The sociotechnical perspective", in A. H. Van de Ven \& W. F. Joyce (Eds.), Perspectives on organization design and behavior (pp.19-75), New York, John Wiley \& Sons.

VANSINA, L. \& TAILLIEU, T. (1996), "Reengenharia do processo de negócio ou desenho de sistemas sociotécnicos em roupas novas", Comportamento Organizacional e Gestão, 2, 63$-82$.

WILLIAMSON, O. E. \& OUCHI, W. G. (1981), "The markets and hierarchies program of research", in A. H. Van de Ven \& W. F. Joyce (Eds.), Perspectives on organization design and behavior (pp.347-370), New York, Wiley.

ZALD, M. N. (1993), “Organization studies as a scientific and humanistic enterprise: toward a reconceptualization of the foundations of the field", Organization Science, 4, 4, 513-528. 